\title{
COMMENTARY
}

\section{What Family Medicine Can Learn From Other Specialties}

Warren Newton, MD, MPH; Michael Magill, MD

(Fam Med. 2021;53(7):606-7.)

doi: 10.22454/FamMed.2021.976389

Published Online First May 26, 2021

$\boldsymbol{F}$ amily medicine is not the only specialty with passionate commitment to excellence in residency education and the formation of young physicians. The major revision of the program requirements for family medicine and the related American Board of Family Medicine (ABFM) policy on board eligibility can take inspiration from other specialties to individualize resident experience, enhance evaluation, and perhaps offer an innovative fourth-year experience to help residents master the increasingly complex reality of family practice.

A first option would be to adapt residents' experiences to meet individual learning needs and support career development. Pediatrics is leading development of formal individualized learning plans ${ }^{1}$ during residencies. These are similar to our "areas of concentration," but with 6 months and typically more specificity and rigor. Developing such plans inevitably raises the question of the value of some of the rotations in our current requirements.

What we give up when we must change is important evidence of what we value. In the summer of 2020, the ABFM asked program directors what rotations they had eliminated in response to the pandemic. Programs most often cancelled subspecialty surgery, elective, and nursing home experiences. In parallel, and in preparation for the summit the Association of Family Medicine Residency Directors surveyed residency directors and the ABFM surveyed residents and residency faculty to ask what curriculum should be eliminated to make room in the curriculum for new requirements that might come with the new standards. ${ }^{3,4}$ There was significant agreement that inpatient surgery, most subspecialty surgical rotations, electives, and inpatient pediatrics could be considered for removal, seemingly reflecting concern about the passive education in many subsurgical rotations and ineffective use of elective time. The surveys thus suggest that there is potential curricular space to individualize training in support of career development and help residents move beyond proficiency to mastery. We might think of offering "Areas of Concentration on Steroids," with more time, better focus, and accomplishment.

A second option is to conduct an in-person oral examination and assessment of clinical skills at the end of residency. The cultural, logistical, and financial challenges of adding this kind of intense individualized assessment would be daunting in family medicine. But many other specialties do this, including many surgical disciplines, physical medicine and rehabilitation, and emergency medicine. Our colleagues in these fields have learned how to conduct oral exams fairly, and they distinguish between the knowledge typically assessed in an examination with multiple choice questions and judgement and clinical decisionmaking uniquely assessable in oral examinations by trained examiners. One of the best examples is in the American Board of Urology, which combines an oral examination in combination with a practice log covering the first 16 months in practice, a description of the practice demographics, peer review from community urologists and explicit attention

From the American Board of Family Medicine, Lexington, KY (Drs Newton and Magill); Department of Family Medicine, University of North Carolina - Chapel Hill (Dr Newton): and Department of Family and Preventive Medicine, University of Utah, Salt Lake City, UT (Dr Magill). 
to professionalism and the ethics of practice, ${ }^{5}$ with particular emphasis on performance of unnecessary procedures. Surely judgement, clinical decision-making, and professionalism are critical for family physicians as we manage multimorbid patients with difficult family situations and challenging social contexts across the continuum of care!

Another example is in anesthesiology. To better assess clinical skills, the American Board of Anesthesiology has incorporated objective structured clinical examinations of communication and point-of-care ultrasound into the final component of board certification. For example, they ask candidates to demonstrate ability to deliver bad news. ${ }^{6}$ Our anesthesia colleagues report that this kind of assessment has identified residents with excellent test scores but poor communications skills, and that these changes in certification have led to dramatic changes in anesthesia residencies. What about us? Family medicine has substantial experience and expertise with objective structured clinical examinations and in behavioral health and doctor-patient communication; do we think that assessment of communication-or, indeed, point-of-care ultrasound-is important enough to develop a national system to assure competence in all graduating residents?

A third option may be the most challenging: we could add a year of required clinical experience. As argued in this issue by Alan Douglass, MD, our current 3-year curriculum feels like an overstuffed potato to many in our community. Family medicine is complex, and is becoming more complex as family physicians lean into emerging clinical and health care problems such as opiate addiction, exploding multimorbidity, deeply disintegrated care, structural determinants of health and health equity. How might we implement a fourth year of experience in family medicine? We have several options. The Length of Training pilot program $^{7-9}$ has shown the potential value of a fourth year of residency and has helped grow support for adding a fourth year, but still only a minority of residency program directors, faculty, and residents support it. ${ }^{10,11}$ Traditional Accreditation Council for Graduate Medical Educationaccredited fellowships such as sports medicine, hospice and palliative medicine, or geriatrics might also count, as would any of the myriad of informal extra-year fellowships such as faculty development, maternity care, or hospitalist care that exist now or could be developed. Keeping in mind the intense education typical of the first year out in practice, a final option might be a mentored experience in the first year in practice, such as in a frontier, underserved, or other practice setting, prior to board certification. The rationale would be both practical and developmental. The focus would be on developing new skills and professionalism, and just enough structure to support learning.

CORRESPONDING AUTHOR: Address correspondence to Dr Warren Newton, American Board of Family Medicine, 1648 McGrathiana Pkwy, Suite 550, Lexington, KY 40511 919-604-1241. WNewton@theabfm.org.

\section{References}

1. ACGME Program Requirements for Graduate Medical Education in Pediatrics. Chicago: Accreditation Council for Graduate Medical Education; 2020. https://www.acgme. org/Portals/0/PFAssets/ProgramRequirements/320_Pediatrics_2020.pdf?ver=2020-06-29-162726-647. Accessed May 1, 2021.

2. AFMRD Guidelines for Individual Areas of Concentration. Leawood, KS: Association of Family Medicine Residency Directors. http://glfhc.org/residency/wp-content/assets/ sites/7/2017/07/AFMRD-AOC_individual_guidelines.pdf. Accessed May 2, 2021.

3. AFMRD Survey on ACGME Program Requirement Revisions. 2020. https://static1.squarespace.com/ static/5ef55bb3b8ab0958a88de0ac/t/5f613e96038ef679ebb3 881f/1600208535779/AFMRD+Survey+on+ACGME+Progr am+Requirement+Revisions.pdf. Accessed May 1, 2021.

4. Starfield Summit IV: Re-Envisioning Family Medicine Residency Education Community Dialogue Survey Results. https://residency.starfieldsummit.com/community-dialogue. Accessed May 1, 2021.

5. Thrasher JB, Hamady CR, Franklin LW. Medical professionalism is like pornography: you know it when you see it. J Am Board Fam Med. 2020 Sep-Oct;33(Suppl):S62-S64. doi: 10.3122/jabfm.2020.S1.190408.

6. ABA Launches OSCE for Certification [press release]. Raleigh, NC: American Board of Anesthesiology; March 29, 2018. https://aba-thelatest.org/2018/03/aba-launches-oscefor-certification/. Accessed May 1, 2021.

7. Eiff MP, Ericson A, Uchison EW, et al. A comparison of residency applications and match performance in 3-year vs 4 -year family medicine training programs. Fam Med. 2019;51(8):641-648. doi:10.22454/FamMed.2019.558529

8. Carney PA, Ericson A, Conry CM, et al. Financial considerations associated with a fourth year of residency training in family medicine: findings from the Length of Training Pilot Study. Fam Med. 2021;53(4):256-266. doi:10.22454/ FamMed.2021.406778

9. Tepperberg S, Barnett KG, Fischer J, Johnson M, Coles $\mathrm{S}$, Hines T. Training toward our future: questions about length of training in family medicine programs. Fam Med. 2019;51(8):636-637. doi:10.22454/FamMed.2019.711802

10. Re-envisioning Family Medicine Residency Education: Faculty. 2020. https://static1.squarespace.com/ static/5ef55bb3b8ab0958a88de0ac/t/5fdb81a8dc9a6b6cb05 a24b0/1608221096476/Faculty_All_201214_.pdf. Accessed May 3, 2021.

11. Re-Envisioning Family Medicine Residency Education: Q1 Year of Expected Graduation from Residency. 2020. https:// static1.squarespace.com/static/5ef55bb3b8ab0958a88de0ac/ t/5fdb81cb1b50515c6a61350f/1608221131118/Resident_ All_201214_pdf. Accessed May 3, 2021. 